\title{
Interactive comment on "Characteristics of Water Masses in the Atlantic Ocean based on GLODAPv2 data" by Mian Liu and Toste Tanhua
}

\author{
Mathias Tomczak (Referee) \\ matthias.tomczak@flinders.edu.au \\ Received and published: 6 February 2019
}

The paper uses the most comprehensive ocean database to objectively define source water types for the Atlantic Ocean.

The paper is put sloppily together and will require a careful reading by someone not too close to the original manuscript to iron out the many grammatical errors and other inconsistencies. I do not consider it the role of the reviewer to do that, but here are a few pointers as to what has to be done:

a) The reference "Schaffer, A.J., JACOBSEN, A.W., Mikulicz's syndrome: a report of ten cases. American Journal of Diseases of Children 34, 327-346, 1927" has no place in an oceanography paper. I assume that, in an effort to be as comprehensive on the 
history of water mass analysis as possible, the author meant "Jacobsen, J P. (1927) Eine graphische Methode zur Bestimmung des Vermischungskoeffizienten im Meer. Gerlands Beiträge zur Geophysik, 16, 404-412" and went astray in his Google search.

b) "The ocean is thus composed a large number of water masses" misses the word "of", and similar with many sentences.

Interactive

c) "Source water type" is sometimes abbreviated as SWT, sometimes as STW.

d) "Based on the work of (Pollard and Pu, 1985)" should be "Based on the work of Pollard and Pu (1985)", and similar with many citations.

Turning to the scientific content of the paper, it may be noted that there are basically two approaches to derive objective definitions of water masses and their source water types. Assuming no knowledge of the situation under study one might try cluster analysis and discover the relevant source water types from that. If, on the other hand, sufficient information is available to predict the source water regions with certainty one might proceed with an analysis of the parameter distributions in the preselected source water regions and derive the source water types from that. Given the large amount of information available for the Atlantic Ocean the paper rightly proceeds along the second path.

Unfortunately, the paper does not fully grasp one of the basics of water mass theory, namely the distinction between water masses formed by subduction and water masses formed by winter-time deep convection. The water masses of the deep ocean are mostly formed by winter-time deep convection. Source water types of the latter variety represent the conditions in their source regions during winter and can therefore be mathematically described by a single point in parameter space, with an associated variance representing interanual changes during water mass formation. The variable values given in Table 3 for the lower three layers can thus bee seen as a listing of the SWTs for the corresponding water masses, which are defined through single points in parameter space.

Printer-friendly version

Discussion paper 
The water masses of the upper ocean (known as Central Waters), on the other hand, are formed by subduction over extensive ocean regions of the subtropics and therefore characterized not by points in parameter space but by usually nearly linear parameter relationships. This is clearly seen in Figure 3, where the TS-relationship of ENACW stretches from 10 to $15^{\circ} \mathrm{C}$ and 35.2 to 36.2 in salinity, or in Figures 5 and 6, which show similar TS-relationships for WSACW and ESACW. (This is even occasionally acknowledged in the text, for example in section 3.1.1.) To define these Central Waters through source water types requires two SWTs for each Central Water to define a linear parameter relationship, one at the lower end of the parameter relationship and one at the upper end. The principle is demonstrated in detail in Figure 2 of Tomczak (1999).

The paper states " In this paper we use the concepts and definitions of water masses as given by Tomczak (1999)" but it does not appear to follow this through in full logic. It states when introducing the water masses of the upper layers: "The Upper Layer is occupied by four SWTs called central waters that are known to be formed by subducted [sic] into the thermocline (Sprintall and Tomczak, 1993; Tomczak and Godfrey, 2013) into the interior of the ocean (Pollard et al., 1996). Figure 2 illustrate [sic] a schematic of the main currents in this layer and the main formation regions of the central waters in the Atlantic Ocean. Water masses or SWTs in this layer can be easily recognized âĂĺby their linear T-S relationship."

There is complete confusion between water masses and SWTs here. The correct description would read: "The Upper Layer is occupied by four water masses called Central Waters that are known to be formed by subduction into the thermocline (Sprintall and Tomczak, 1993; Tomczak and Godfrey, 2013). Figure 2 illustrates a schematic of the main currents in this layer and the main formation regions of the Central Waters in the Atlantic Ocean. Water masses in this layer can be easily recognized âẤlby their linear T-S relationship, and each water mass requires two SWTs to represent this relationship for a complete description."

The problem of the Central Waters continues right through the paper. If the criteria

OSD

Interactive comment
Printer-friendly version

Discussion paper 
used to define ENACW pick up all data points along the linear parameter relationship of Figure 2, what is the meaning of the variable values given for ENACW in Table 3? Those values do not describe a parameter relationship but a single parameter point in space not representative of Central Water. The representation of the Central Waters in Figure 22 also does not correspond to the definition ranges shown in Figures 2, 5 and 6. Central Waters should show up in Figure 22 as TS-lines, not TS-points. (As an aside, I assume that "F ISOW" in the figure caption should read "K ISOW".)

To summarize the review up to this point, the paper has to address the description of Central Waters afresh and make a clear distinction between subducted water masses and water masses formed by deep convection.

There are other points of a minor nature that nevertheless require attention. Figure 22 shows a sequence of data points near 34.8 salinity reaching down to temperatures as low as $-1.5^{\circ} \mathrm{C}$. Such data points cannot be produced by mixing between any of the SWTs shown, so they represent an additional SWT. At least a remark is required what these data points stand for and why they are not considered further.

The paper states "Mode Waters, on the other âĂíhand, are considered as the precursor or the prototype of the central waters." This is not necessarily so. The quasi-linear parameter relationship of Central Water does not relate linearly to depth. Some depth ranges within the Central Waters display rapid parameter changes with depth, others show particularly uniform properties. Mode Waters are sub-regions of Central Water; they describe such layers within the Central Water range that display particularly uniform properties.

Finally, in a combined TS-diagram of data from a region SWTs are normally identified as the extreme TS-points that cannot be produced by mixing with other water masses. The definition points for AAIW in Figure 8 clearly include TS-combinations influenced by admixtures from NADW and even Central Water. A definition of AAIW based on its source region will have to concentrate on the low salinity points in the 0 to $2^{\circ} \mathrm{C}$ range.

OSD

Interactive comment
Printer-friendly version

Discussion paper 
Some commentary is necessary to justify the selection of definition points in Figure 8.

OSD

Interactive comment on Ocean Sci. Discuss., https://doi.org/10.5194/os-2018-139, 2019.

Interactive

comment 